\title{
Formation, stability and antioxidant activity of food-grade multilayer emulsions containing resveratrol
}

\author{
Alejandra Acevedo-Fani ${ }^{a}$, Hélder Daniel Silva ${ }^{\mathrm{b}}$, Robert Soliva-Fortuny ${ }^{\mathrm{a}}$, \\ Olga Martín-Belloso ${ }^{\mathrm{a}, *}$, Antonio A. Vicente ${ }^{\mathrm{b}}$ \\ a Department of Food Technology, University of Lleida - Agrotecnio Centre, Av. Alcalde Rovira Roure 191, 25198, Lleida, Spain \\ b Centre of Biological Engineering, University of Minho, Campus de Gualtar, 4710-057, Braga, Portugal
}

\section{A R T I C L E I N F O}

Article history:

Received 8 October 2016

Received in revised form

10 April 2017

Accepted 8 May 2017

Available online 17 May 2017

\section{Keywords:}

Multilayer emulsions

Layer-by-layer deposition

Resveratrol

Lactoferrin

Alginate

Poly-L-lysine

\begin{abstract}
A B S T R A C T
Interfacial deposition of biopolymer layers on oil droplets may be a suitable strategy for increasing the emulsion stability and protection of functional ingredients. Resveratrol is a naturally occurring phenolic compound with numerous health-promoting properties, but its usage is still restricted due to its poor water solubility and high chemical instability. The aim of this study was to formulate single-layer (lactoferrin) and multilayer (lactoferrin/alginate and lactoferrin/alginate/e-poly-L-lysine) emulsions containing resveratrol and to study the emulsions stability and antioxidant activity during storage. All primary (single-layer) emulsions had average droplet diameters below $300 \mathrm{~nm}$ and $\zeta$-potentials strongly positive, allowing the electrostatic deposition of another layer of anionic biopolymer, such as alginate. Secondary (multilayer) emulsions were highly unstable at low alginate concentrations, which was attributed to the bridging flocculation. At higher alginate concentrations, secondary emulsions were rather stable. Tertiary emulsions containing either low or high $\varepsilon$-poly-L-lysine concentrations presented flocculation, but formulations with $0.0036 \%(\mathrm{w} / \mathrm{w})$ were fairly stable. The antioxidant activity of all resveratrol-loaded emulsions did not significantly change during storage, whereas it decreased in nonencapsulated resveratrol oil from the third week onwards. This study provides useful information for the design of delivery systems for resveratrol with relevance in food applications.
\end{abstract}

(C) 2017 Elsevier Ltd. All rights reserved.

\section{Introduction}

Encapsulating active food ingredients for their incorporation in food products is still a challenging task to the food industry. The use of nanostructured delivery systems, such as multilayer emulsions, might be a potential strategy to reach this goal. Multilayer emulsions are emulsions with oil droplets coated by more than one interfacial layer of charged emulsifiers and/or biopolymers, created by the stepwise electrostatic deposition of oppositely charged materials (Bortnowska, 2015; McClements, Decker, Park, \& Weiss, 2009). Previous findings have shown that multilayer emulsions are highly stable to $\mathrm{pH}$ changes, high ionic strength, temperature (either heating or freezing) and dehydration, due to the presence of a thick interfacial layer (Fioramonti, Arzeni, Pilosof, Rubiolo, \& Santiago, 2015; Liu, Wang, Sun, McClements, \& Gao, 2016; Noshad, Mohebbi, Koocheki, \& Shahidi, 2015; Schmelz, Lesmes,

\footnotetext{
* Corresponding author.

E-mail address: omartin@tecal.udl.cat (O. Martín-Belloso).
}

Weiss, \& McClements, 2011). This physical property might potentially enhance the protection of sensitive active ingredients encapsulated in these systems. In addition, the composition of the interfacial coating can be designed so that multilayer emulsions respond to specific triggers, releasing encapsulated ingredients (Cerqueira et al., 2014; Guzey \& McClements, 2006; Shchukina \& Shchukin, 2012).

Proteins and polysaccharides are suitable materials to produce multilayer emulsions since they can be used either as emulsifiers or as building blocks for the multilayer coatings. Lactoferrin is an ironchelating glycoprotein mainly found in the breast milk of mammalian species, which plays an important role in the defense system due to its antimicrobial, antiviral and antioxidant properties (O'Regan, Ennis, \& Mulvihill, 2009). From a technological point of view, lactoferrin is a cationic polyelectrolyte at neutral $\mathrm{pH}$ because of its high isoelectric point ( $\mathrm{pI} \approx 9$ ) (Bokkhim, Bansal, GrØndahl, \& Bhandari, 2013). Previous studies indicate that lactoferrin has excellent emulsifying capacity, forming small droplet size o/w emulsions (Mao, Dubot, Xiao, \& McClements, 2013; Pinheiro, Coimbra, \& Vicente, 2016; Shimoni, Shani Levi, Levi Tal, \& 
Lesmes, 2013) and rather stable systems in the presence of divalent ions (McCarthy, Kelly, O'Mahony, \& Fenelon, 2014). Lactoferrin, used either as additive in the emulsion or deposited at the $\mathrm{o} / \mathrm{w}$ interface, has been shown to increase the chemical stability of emulsions (Lesmes, Sandra, Decker, \& McClements, 2010; Nina S. Nielsen, Petersen, Meyer, Timm-Heinrich, Jacobsen, Nielsen, \& Jacobsen, 2004). Alginate is a polysaccharide widely used as a thickening agent in food products. Since alginate exhibits anionic properties above its $\mathrm{p} K_{\mathrm{a}}(\approx 3.6)$, it is one of the polysaccharides mostly utilized to produce food-grade nanostructures through electrostatic interactions (Bokkhim, Bansal, Grøndahl, \& Bhandari, 2016; Chang, McLandsborough, \& McClements, 2014; Choi, Kim, Cho, Hwang, \& Kim, 2011; Hosseini, Emam-Djomeh, Sabatino, \& Van der Meeren, 2015). The $\varepsilon$-poly-L-lysine is a polypeptide with cationic properties at neutral $\mathrm{pH}$ due to its high isoelectric point ( $\mathrm{p} I \approx 9)$. The importance of $\varepsilon$-poly-L-lysine in the food sector lies on the strong antimicrobial activity over a wide number of pathogenic and spoilage microorganisms (Yoshida, Hiraki, \& Nagasawa, 2005).

Resveratrol is a naturally occurring phenolic compound mainly found in grapes' skin and berry fruits and belongs to the stilbenes family. Several investigations have evidenced important biological properties for resveratrol, including antioxidant activity, antiinflammatory, anti-carcinogenic, cardio-protective or neuroprotective effect (Brown et al., 2010; Kim, Jin, Choi, \& Park, 2011; Park et al., 2012; Witte, Kerti, Margulies, \& Flöel, 2014; Xu \& Si, 2012). For these reasons, there is an increasing interest in the use of resveratrol as nutraceutical in food products. However, resveratrol has poor water solubility (Amri, Chaumeil, Sfar, \& Charrueau, 2012; Zupančič, Lavrič, \& Kristl, 2015) and is highly sensitive to environmental stresses. In fact, the resveratrol molecule shows extensive photo-isomerization under UV light exposure (DavidovPardo \& McClements, 2014; Trela \& Waterhouse, 1996). It has been described that resveratrol encapsulation into food-grade delivery systems, such as emulsions, might be a feasible alternative to reduce the above-mentioned drawbacks (Davidov-Pardo \& McClements, 2014).

Previously, lipophilic and highly sensitive active ingredients have been encapsulated into single-layer emulsions, observing their rapid chemical degradation and emulsion instability at extreme $\mathrm{pH}$ and temperature conditions during storage (DavidovPardo, Gumus, \& McClements, 2016). Considering that multilayer emulsions are highly stable systems to several stressing conditions, it was hypothesized that these systems might be a potential delivery system for resveratrol. On the other hand, the formation and stability of multilayer emulsions depend on several factors such as droplet size, droplet concentration, or biopolymer concentration in the emulsion, and processing parameters including $\mathrm{pH}$, ionic strength, dielectric constant, temperature or stirring as well (Guzey \& McClements, 2006; Ye \& Singh, 2007).

The biopolymer concentration in aqueous phase significantly affects the stability of the system and can lead to droplets flocculation (Bouyer, Mekhloufi, Rosilio, Grossiord, \& Agnely, 2012). Previous studies have shown that the stability of multilayer emulsions containing protein-stabilized droplets and polysaccharides can change from stable, unstable to stable, by increasing the polysaccharide concentration from zero to a relatively high amount (Cho \& McClements, 2009). Therefore, finding an adequate biopolymer concentration for preparing multilayer emulsions is crucial to obtain stable systems. The objective of the present work was to evaluate the effect of the biopolymer concentration on the formation of primary (lactoferrin-coated droplets), secondary (lactoferrin/alginate-coated droplets) and tertiary (lactoferrin/ alginate/ع-poly-L-lysine-coated droplets) emulsions containing resveratrol. The physical stability and antioxidant activity of the emulsions were examined during storage.

\section{Materials and methods}

\subsection{Materials}

Resveratrol extracted from grape skin (purity > 99\%) was kindly supplied by Changsha Organic Herb Inc./Phyto Nutraceutical Inc. (Changsha, China). Corn oil (Fula ${ }^{\circledR}$, Sovena, Portugal) was purchased from a local supermarket. Lactoferrin was obtained from DMV International (Veghel, The Netherlands). The composition provided by the manufacturer and expressed as a dry weigh percentage was: 96\% protein, $0.5 \%$ ash, 3.5\% moisture and $120 \mathrm{ppm}$ iron content. Sodium alginate was purchased from Kelco International, Ltd. (Aberdeen, UK) and $\varepsilon$-poly-L-lysine (Epolyly ${ }^{\circledR}$, MW $30 \mathrm{kDa}$ ) was purchased from Handary S.A (Brussels, Belgium). The 1,1-diphenyl2-picrylhydrazyl radical (DPPH) was purchased from Sigma-Aldrich (Madrid, Spain). All emulsions and biopolymer solutions were prepared with deionized water extracted from a Milli-Q system (Millipore Corp., Massachusetts, USA).

\subsection{Preparation of single-layer and multilayer emulsions}

\subsubsection{Primary emulsions}

The oil phase of emulsions was prepared by dissolving resveratrol powder in small amounts of absolute ethanol and incorporating the previous blend to corn oil, followed by mixing in a vortex for $2 \mathrm{~min}$ to ensure the complete resveratrol dispersion. Ethanol was used as a co-solvent to enhance dissolution of resveratrol crystals in oil (Sessa, Tsao, Liu, Ferrari, \& Donsì, 2011). The concentration of ethanol in corn oil was $0.04 \mathrm{~g} / \mathrm{g}$. The lipid phase was homogenized with the aqueous phase containing the emulsifier agent (lactoferrin solutions at $1.0 \%, 1.5 \%$ and $2.0 \% \mathrm{w} / \mathrm{w}, \mathrm{pH} \approx 5.3$ ) using a high-shear blender at $5000 \mathrm{rpm}$ for $2 \mathrm{~min}$ (Ultra-turrax T25, IKA Werke, Staufen, Germany). The final systems contained $0.01 \%$ $\mathrm{w} / \mathrm{w}$ resveratrol, $0.20 \% \mathrm{w} / \mathrm{w}$ ethanol, $5.00 \% \mathrm{w} / \mathrm{w}$ corn oil, and $0.95 \%$ $\mathrm{w} / \mathrm{w}, 1.42 \% \mathrm{w} / \mathrm{w}$ or $1.90 \% \mathrm{w} / \mathrm{w}$ lactoferrin. Afterwards, a second homogenization was carried out in a high-pressure homogenizer (Nano DeBEE, BEE International, USA) at 22,000 psi and 5 cycles. In this case, the term 'primary emulsions' was referred to emulsions with oil droplets coated by a single lactoferrin layer. Primary emulsions were adjusted to $\mathrm{pH} 5$ using $0.1 \mathrm{M} \mathrm{HCl}$. Formulations that obtained the smallest droplet size and sufficiently strong electrical charge (as measured by $\zeta$-potential) were selected for assembling a second alginate interfacial layer.

\subsubsection{Secondary emulsions}

To prepare secondary emulsions, $5 \mathrm{~mL}$ of sodium alginate solutions at different concentrations and $15 \mathrm{~mL}$ of water were added to $5 \mathrm{~mL}$ of primary emulsions under continuous stirring and at a dripping rate of $10 \mathrm{~mL} / \mathrm{min}$. The resulting emulsions contained $0.002 \% \mathrm{w} / \mathrm{w}$ resveratrol, $1.00 \% \mathrm{w} / \mathrm{w}$ corn oil, $0.38 \% \mathrm{w} / \mathrm{w}$ lactoferrin, and from $0.02 \%$ to $0.28 \% \mathrm{w} / \mathrm{w}$ alginate. All components were previously adjusted to $\mathrm{pH} 5$, since at this $\mathrm{pH}$ biopolymers would be sufficiently charged to form electrostatic complexes. Emulsions were stirred for 15 additional min at room temperature. Secondary emulsions were sonicated for $10 \mathrm{~min}$ to disrupt possible flocs formed during alginate adsorption. In this case, the term 'secondary emulsions' was referred to emulsions with oil droplets coated by lactoferrin-alginate layers. The most stable formulation was used for assembling a third $\varepsilon$-poly-L-lysine interfacial layer.

\subsubsection{Tertiary emulsions}

To form tertiary emulsions, $5 \mathrm{~mL}$ of $\varepsilon$-poly-L-lysine solutions at different concentrations and $45 \mathrm{~mL}$ of water were added to $5 \mathrm{~mL}$ of secondary emulsions under continuous stirring and at a dripping rate of $10 \mathrm{~mL} / \mathrm{min}$. The final composition of emulsions was $0.0002 \%$ 
w/w resveratrol, $0.090 \%$ corn oil, $0.030 \% \mathrm{w} / \mathrm{w}$ lactoferrin, $0.020 \% \mathrm{w} /$ $\mathrm{w}$ alginate, and from $0.009 \%$ to $0.045 \% \mathrm{w} / \mathrm{w}$-poly-L-lysine. The biopolymer solutions, water and emulsions were adjusted to $\mathrm{pH} 5$ before blending them to induce alginate/e-poly-t-lysine electrostatic interactions. Mixtures were stirred for 15 additional min at room temperature. Finally, tertiary emulsions were sonicated as described in section 2.2.2. In this case, the term 'tertiary emulsions' was referred to emulsions with oil droplets coated by lactoferrinalginate-e-poly-L-lysine layers.

\subsection{Droplet size and polydispersity index measurements}

The droplet size of the emulsions was determined by dynamic light scattering in a laser diffractometer (Zetasizer NanozS, Malvern Instruments, Worcestershire, U.K.), fitted with a laser at $633 \mathrm{~nm}$ and a backscatter detector $\left(173^{\circ}\right)$ at $25^{\circ} \mathrm{C}$. Primary and secondary emulsions were diluted prior to analysis with ultrapure water $(\mathrm{pH}$ $5)$ at a ratio of $1: 100(\mathrm{v} / \mathrm{v})$ to avoid multiple scattering effects. Tertiary emulsions were analyzed at a ratio of 1:10 (v/v). Measurements were performed in triplicate.

\section{4. $\zeta$ - potential measurements}

The electrophoretic mobility of the droplets was analyzed by Laser Doppler Velocimetry (LDV) and converted into క-potentials using the Smoluchowski equation in a Zetasizer Nano ZS device (Malvern Instruments, Worcestershire, U.K.). Primary and secondary emulsions were diluted prior to analysis with ultrapure water $(\mathrm{pH} 5)$ at a ratio of $1: 100(\mathrm{v} / \mathrm{v})$, whereas tertiary emulsions were analyzed $1: 10(\mathrm{v} / \mathrm{v})$ by placing samples in plastic zeta cells (DTS 1061, Malvern, UK), and equilibrating them at $25^{\circ} \mathrm{C}$ during $60 \mathrm{~s}$. Analyses were performed in triplicate.

\subsection{Short-term stability}

The physical stability of single-layer and multilayer emulsions was analyzed through changes in their size and interfacial electrical charge. Analyses of droplet size and $\zeta$-potentials were performed as described in sections 2.3 and 2.4. Emulsions were stored in conical centrifuge tubes of $15 \mathrm{~mL}$ (Falcon ${ }^{\mathrm{TM}}$, Fisher Scientific) during four weeks at room temperature $\left(\approx 25^{\circ} \mathrm{C}\right)$ and lighting. Emulsions were examined every seven days. Two independent runs were carried out for each emulsion type.

\subsection{Transmission electron microscopy imaging}

The morphology of single-layer emulsions and multilayer emulsions was evaluated by transmission electron microscopy (TEM) (EM 902A, ZEISS, Germany) operating at $80 \mathrm{kV}$. TEM samples were prepared by depositing the single-layer emulsions and multilayer emulsions suspensions on a carbon-coated copper grid, and negatively stained with $1 \%(\mathrm{w} / \mathrm{v}$ ) uranyl acetate for observation. Samples were air-dried before analyses.

\subsection{Antioxidant activity}

The scavenging effect of resveratrol-enriched corn oil, primary, secondary and tertiary emulsions on $\mathrm{DPPH}^{\bullet}$ radical was evaluated through a method described by Pinheiro et al., (2015) with some modifications. Briefly, $1 \mathrm{~mL}$ of each emulsion was blended with $4 \mathrm{~mL}$ of ethanol absolute to promote the emulsion leakage and release of resveratrol. Then, an aliquot of $0.3 \mathrm{~mL}$ was mixed with $0.2 \mathrm{~mL}$ of ethanol absolute and $2.5 \mathrm{~mL}^{\circ} \mathrm{DPPH}^{\bullet}$ solution $(60 \mu \mathrm{M}$ in ethanol) in a $10 \mathrm{~mL}$ test tube, achieving a total volume of $3.0 \mathrm{~mL}$. Solutions were kept under dark conditions during $30 \mathrm{~min}$ at room temperature to carry out the reaction. Absorbance was measured at $515 \mathrm{~nm}$ using a Multi-Detection Microplate Reader Synergy ${ }^{\mathrm{TM}}$ HT (Biotek, Winooski, USA). The radical scavenging activity of emulsions was calculated through Eq. (1) as follows:

Scavenging Effect $(\%)=\left(\frac{A_{0}-A}{A_{0}}\right) \times 100$

where $A_{o}$ is the absorbance of the $\mathrm{DPPH}^{\bullet}$ solution and $A$ is the absorbance of the sample with $\mathrm{DPPH}^{\bullet}$. Two independent experiments were carried out and samples were analyzed in triplicate.

\subsection{Statistical analysis}

Data were analyzed through a one-way analysis of variance (ANOVA) using the statistical and graphing software SigmaPlot 11.0 Windows package (Systat software Inc.). The Holm-Sidak method was used to determine significant differences among mean values at $5 \%$ of significance level. All results are presented as the average results and standard deviations.

\section{Results and discussion}

\subsection{Effect of lactoferrin concentration on the primary emulsions formation}

The properties of primary emulsions were significantly affected by the lactoferrin concentration in the aqueous phase $(p<0.05)$ (Table 1). The droplet size decreased as the lactoferrin concentration increased in primary emulsions, reaching $187 \mathrm{~nm}$ at $1.90 \% \mathrm{w} / \mathrm{w}$. However, all formulations presented very small droplet sizes $(<300 \mathrm{~nm})$. The polydispersity index (PdI) also decreased in emulsions containing the highest lactoferrin concentration. The droplet size distributions of primary emulsions with a lactoferrin concentration below $1.42 \% \mathrm{w} / \mathrm{w}$ were multimodal, characterized by a main broad peak around $400 \mathrm{~nm}$ and a minor intensity peak around $4000 \mathrm{~nm}$ (that was not completely detected by the measurement device) (Fig. 1). This result indicated that some bigger droplets were not disrupted during homogenization, or that the lactoferrin concentration was not enough to saturate the interface of newly oil droplets created, thus leading to their coalescence. However, primary emulsions containing $1.90 \% \mathrm{w} / \mathrm{w}$ lactoferrin presented monomodal particle size distributions, indicating that sufficient concentration of lactoferrin was available to adsorb at the surface of newly created oil droplets. It has been established that nanometric size emulsions (between 20 and $200 \mathrm{~nm}$ ) are more stable to gravitational separation and particle aggregation than conventional emulsions (McClements \& Rao, 2011), and this feature is especially important to produce stable multilayer emulsions.

The electrical charge ( $\zeta$-potential) of lactoferrin-coated droplets was strongly positive regardless the lactoferrin concentration, ranging from $45 \mathrm{mV}$ to $50 \mathrm{mV}$. This confirmed that lactoferrin molecules were adsorbed at the $\mathrm{o} / \mathrm{w}$ interface of droplets forming cationic interfacial layers. A strong interfacial electrical charge not only increases the emulsions stability due to the strong repulsive forces among droplets, but also allows the deposition of another interfacial layer of opposite charge. Results obtained in this experiment are in good agreement with others previously published of lactoferrin-stabilized emulsions, where the droplet size and $\zeta$-potential of emulsions containing $1.50 \% \mathrm{w} / \mathrm{w}$ lactoferrin were $\approx 230 \mathrm{~nm}$ and $\approx 50 \mathrm{mV}$, respectively (Zhao, Wei, Wei, Yuan, \& Gao, 2015 ). Based on these results, primary emulsions that contained $1.90 \%(w / w)$ lactoferrin were selected for the formation of secondary emulsions for presenting the smallest droplet size, monomodal particle size distributions and a strong positive $\zeta$-potential. 
Table 1

Droplet characteristics of primary emulsions containing different lactoferrin concentrations.

\begin{tabular}{|c|c|c|c|}
\hline Final lactoferrin concentration $(\% \mathrm{w} / \mathrm{w})$ & Mean droplet diameter $(\mathrm{nm})$ & PdI & $\zeta$-potential $(\mathrm{mV})$ \\
\hline 0.95 & $224 \pm 4^{\mathrm{a}}$ & $0.29 \pm 0.04^{\mathrm{a}}$ & $48.7 \pm 2.1^{\mathrm{a}}$ \\
\hline 1.42 & $289 \pm 3^{b}$ & $0.362 \pm 0.004^{b}$ & $44.4 \pm 1.8^{\mathrm{b}}$ \\
\hline 1.90 & $187 \pm 4^{\mathrm{c}}$ & $0.153 \pm 0.016^{c}$ & $45.8 \pm 0.5^{\mathrm{ab}}$ \\
\hline
\end{tabular}

${ }^{\text {a.b,c }}$ Mean values with same superscript within a column are not significantly different $(\mathrm{p}<0.05)$.

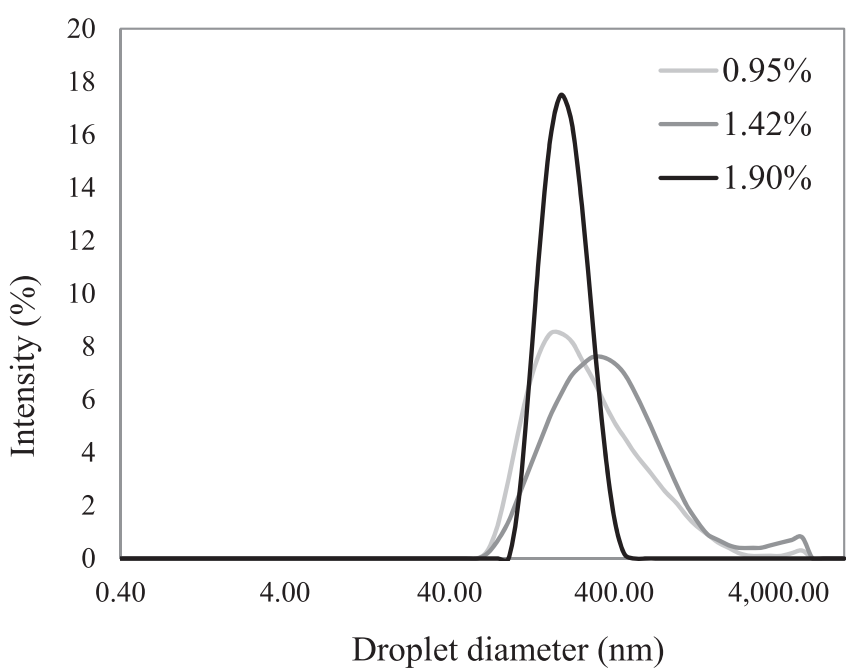

Fig. 1. Droplet size distributions of primary emulsions containing different lactoferrin concentrations in the aqueous phase.

\subsection{Effect of alginate concentration on the secondary emulsions formation}

To create a second interfacial layer on lactoferrin-coated droplets, different concentrations of alginate were tested. The droplet size and $\zeta$-potential were assessed in order to establish the optimal alginate concentration necessary to form stable secondary emulsions. In general, the alginate concentration significantly influenced the droplet size and $\zeta$-potential of secondary emulsions (Fig. 2) $(p<0.05)$. First, there was an abrupt increase in the droplet size from $187 \mathrm{~nm}$ up to $8700 \mathrm{~nm}$ when the alginate concentration increased to $0.02 \% \mathrm{w} / \mathrm{w}$, and the emulsions showed a visible phase separation after 15 min of preparation (Fig. 2A). This result indicated that emulsions presented extensive flocculation at low alginate concentrations, which could be ascribed to a bridging flocculation effect. If the biopolymer concentration in the aqueous phase of emulsions is insufficient to saturate droplets' surface, then a single molecular chain tends to adsorb to the surface of several droplets simultaneously, promoting their aggregation. The droplet size of emulsions have been reported to play a crucial role in the bridging flocculation occurrence. If the droplet size decreases the incidence of bridging flocculation may increase, since the time between droplet collision decreases more rapidly than the time required for droplets surface to be saturated by biopolymers in the aqueous phase (Cho \& McClements, 2009). However, bridging flocculation can be reduced if the biopolymer concentration in the emulsion increases (Dickinson, 2003; Heurtault, 2003; McClements, 2005). This effect was also observed in the secondary emulsions using a higher alginate concentration. The droplet size gradually decreased from $1590 \mathrm{~nm}$ to $589 \mathrm{~nm}$ by increasing alginate concentration from $0.04 \%$ to $0.16 \% \mathrm{w} / \mathrm{w}$ in the aqueous phase, although these emulsions were unstable after $24 \mathrm{~h}$.

At relatively high alginate concentration $(>0.18 \% \mathrm{w} / \mathrm{w})$, the
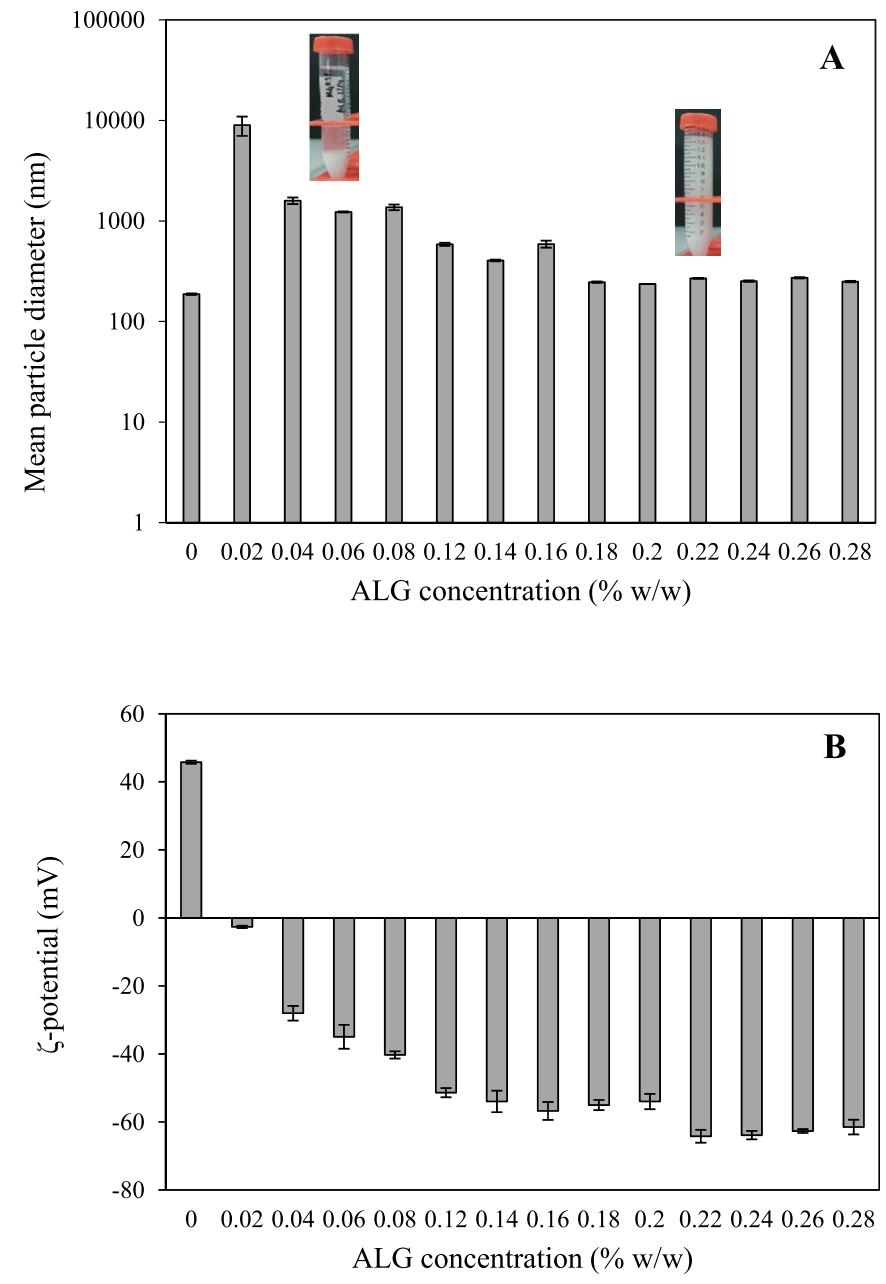

Fig. 2. (A) Droplet size and (B) ל-potential values of secondary emulsions containing different sodium alginate concentrations (ALG). The emulsions composition was $0.002 \% \mathrm{w} / \mathrm{w}$ resveratrol, $1 \% \mathrm{w} / \mathrm{w}$ corn oil, $0.38 \% \mathrm{w} / \mathrm{w}$ lactoferrin, and from $0.02 \%$ to $0.28 \% \mathrm{w} / \mathrm{w}$ alginate.

droplet size decreased even more (249 nm), emulsions were highly stable and droplets did not precipitated after $24 \mathrm{~h}$ (Fig. 2A). This suggested that there was sufficient alginate in the aqueous phase to fully saturate the surface of lactoferrin-coated droplets, thus reducing bridging flocculation.

The initial $\zeta$-potential of lactoferrin-coated droplets $(46 \mathrm{mV})$ significantly decreased to $-2.6 \mathrm{mV}$ in emulsions that contained $0.02 \% \mathrm{w} / \mathrm{w}$ alginate (Fig. $2 \mathrm{~B}$ ). This result suggests that there was a charge neutralization and lactoferrin-coated droplets were barely coated by alginate molecules, since the alginate concentration was insufficient to allow a charge reversal at the positive interface (lactoferrin layer). However, greater concentrations of alginate (from $0.04 \%$ to $0.20 \% \mathrm{w} / \mathrm{w}$ ) led to more negative $\zeta$-potentials (from $-28 \mathrm{mV}$ to $-54 \mathrm{mV}$ ), and hence there were more alginate 
molecules available to be adsorbed onto lactoferrin-coated droplets (Fig. 2B).

By increasing more the alginate concentration $(>0.22 \% \mathrm{w} / \mathrm{w})$ in secondary emulsions, the $\zeta$-potential plateaued, which could be attributed to a complete saturation of the lactoferrin-coated droplets by alginate, forming a new anionic layer. In this case, secondary emulsions were stable due to the strong electrostatic repulsion among droplets. It also means that some unbound alginate molecules were in the aqueous phase of emulsions in which the $\zeta$-potential did not change in spite of the alginate concentration being increased. Unbounded biopolymer chains could lead to emulsions instability either by the formation of electrostatic complexes with oppositely changed species during the preparation of multilayer emulsions or by depletion interactions. For this reason, the formulation of secondary emulsions selected to prepare tertiary emulsions was that containing $0.22 \% \mathrm{w} / \mathrm{w}$ alginate. This emulsion exhibited small droplet size, very negative $\zeta$-potential but without containing excessive unbound alginate chains in the aqueous phase.

\subsection{Effect of $\varepsilon$-poly-L-lysine concentration on the tertiary emulsions formation}

To create a third interfacial layer around alginate/lactoferrincoated droplets, several $\varepsilon$-poly-L-lysine concentrations in the emulsions were investigated. The aim of these experiments was to obtain an optimal $\varepsilon$-poly-L-lysine concentration that allows producing stable tertiary emulsions, this was assessed through changes in the droplet size and droplet charge ( $\zeta$-potential) (Fig. 3).

The average droplet size of tertiary emulsions increased from $298 \mathrm{~nm}$ to $325 \mathrm{~nm}$ at $0.009 \% \varepsilon$-poly-L-lysine. This behavior was more evident when polypeptide concentration increase to $0.018 \%$, with droplet sizes around $870 \mathrm{~nm}$ and instant phase separation of the emulsions after preparation. Results indicate that emulsions were rather unstable containing low polypeptide concentrations in the aqueous phase, which was ascribed to the bridging flocculation. However, a significant decrease in droplet size (417 nm) was observed when the $\varepsilon$-poly-L-lysine concentration increased to $0.036 \% \mathrm{w} / \mathrm{w}$, and in this case tertiary emulsions were visibly stable after $24 \mathrm{~h}$.

At a higher $\varepsilon$-poly-t-lysine concentration $(0.045 \% \mathrm{w} / \mathrm{w})$ in the aqueous phase, the droplet size increased above $1 \mu \mathrm{m}$, evidencing a phase separation in tertiary emulsions (Fig. 3A). Results indicated that emulsions were highly unstable at the highest $\varepsilon$-poly-L-lysine concentration and droplets aggregation occurred, which could be attributed to a depletion flocculation effect. This instability phenomenon takes place in the presence of excessive amounts of nonadsorbed biopolymer in the aqueous phase of emulsions, which cause attractive interactions between droplets and their consequent aggregation (Benjamin, Silcock, Leus, \& Everett, 2012; McClements, 2000).

On the other hand, the magnitude of the electrical charge of alginate/lactoferrin-coated droplets decreased from $-64.2 \mathrm{mV}$ to $-25.6 \mathrm{mV}$, increasing the concentration of $\varepsilon$-poly-L-lysine in emulsions to $0.009 \%(\mathrm{w} / \mathrm{w})$ (Fig. 3B). Although the net charge of the particles was still negative, this decrease suggested that not enough of $\varepsilon$-poly-L-lysine molecules adsorbed on the oil droplets' surface to completely cover them. Probably, the interfacial electrical charge of droplets was the resulting contribution of uncoated negative alginate patches and positive $\varepsilon$-poly-L-lysine patches adsorbed on the droplets' surface. By increasing the $\varepsilon$-poly-L-lysine concentration to $0.018 \%(\mathrm{w} / \mathrm{w})$, the $\zeta$-potential of tertiary emulsions changed to positive values $(25.8 \mathrm{mV})$. At higher $\varepsilon$-poly-L-lysine concentrations $(>0.036 \% \mathrm{w} / \mathrm{w})$, the magnitude of the positive $\zeta$-potential continued increasing in tertiary emulsions. From these results it

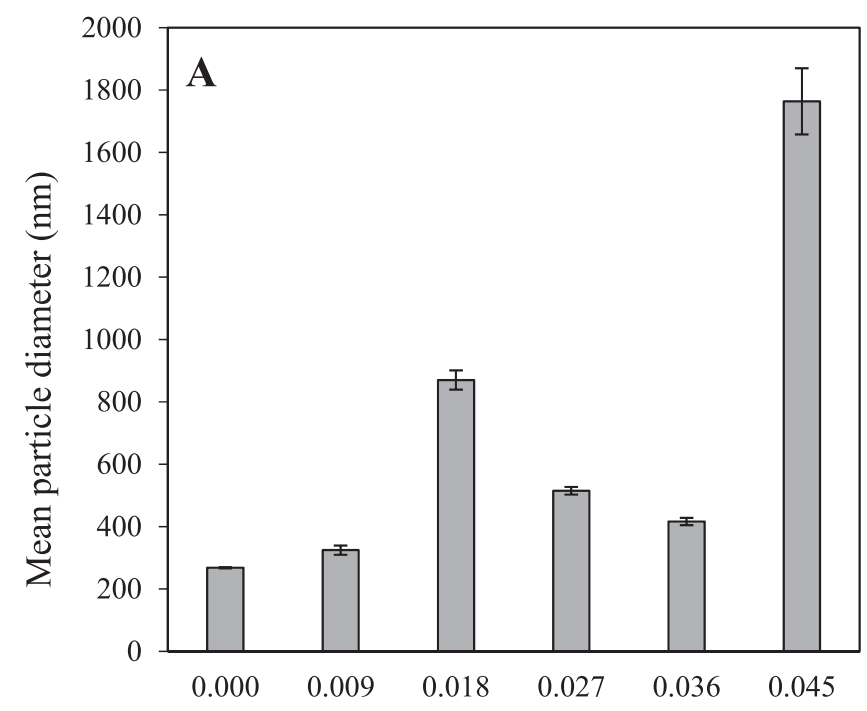

$\varepsilon$-PLL concentration $(\% \mathrm{w} / \mathrm{w})$

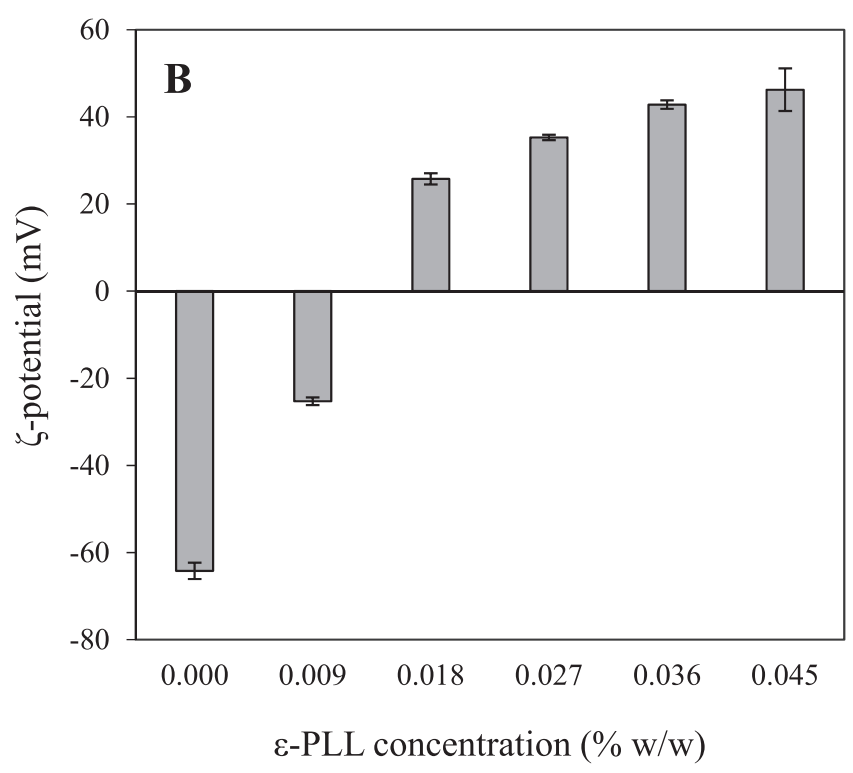

Fig. 3. (A) Droplet size and (B) $\zeta$-potential values of tertiary emulsions containing different $\varepsilon$-poly-L-lysine concentrations ( $\varepsilon$-PLL). Emulsions were composed by $0.0002 \%$ $\mathrm{w} / \mathrm{w}$ resveratrol, $0.090 \% \mathrm{w} / \mathrm{w}$ corn oil, $0.030 \% \mathrm{w} / \mathrm{w}$ lactoferrin, $0.020 \% \mathrm{w} / \mathrm{w}$ alginate, and from $0.009 \%$ to $0.045 \% \mathrm{w} / \mathrm{w}$ e-poly-L-lysine.

was possible to infer that a third interfacial layer was created around droplets, being stabilized by the strong electrostatic repulsion. The optimal formulation of tertiary emulsions selected for the subsequent analyses was that containing $0.036 \% \mathrm{w} / \mathrm{w}$ $\varepsilon$-poly-L-lysine, since these emulsions presented small droplet sizes and strong positive $\zeta$-potential.

\subsection{Short-term stability}

The physical stability of single-layer and multilayer emulsions were evaluated monitoring changes in their droplet size and droplet charge during storage (Fig. 4). Emulsions were maintained at room temperature and lighting, simulating conventional storage 
conditions of non-perishable foods. The initial average droplet size of primary emulsions was $187 \mathrm{~nm}$, and no significant changes were observed after four weeks ( $p<0.05$ ) (Fig. 4A). However, secondary emulsions initially showed a slight increase from $227 \mathrm{~nm}$ to $274 \mathrm{~nm}$ in the second week, maintaining similar average droplet sizes until the end of storage. These results could be attributed either to a flocculation phenomenon or to the subsequent adsorption of remaining free alginate molecules at the $\mathrm{o} / \mathrm{w}$ interface during storage. Changes in the particle size distributions were also observed after 14 days (data not shown), observing small intensity peaks in the micrometric region that suggests the presence of bigger particles, probably originated due to the flocculation of smaller droplets. The initial droplet diameters of tertiary emulsions decreased from $416 \mathrm{~nm}$ to $388 \mathrm{~nm}$ in the second week. This could be ascribed to rearrangements of $\varepsilon$-poly-L-lysine chains at the interface into a denser molecular packing, resulting in a smaller hydrodynamic diameter. It has been previously reported that multilayered structures are formed by an initial rapid adsorption of the molecular chains to the substrate, followed by slow changes in chains' conformation until reaching an energetic equilibrium
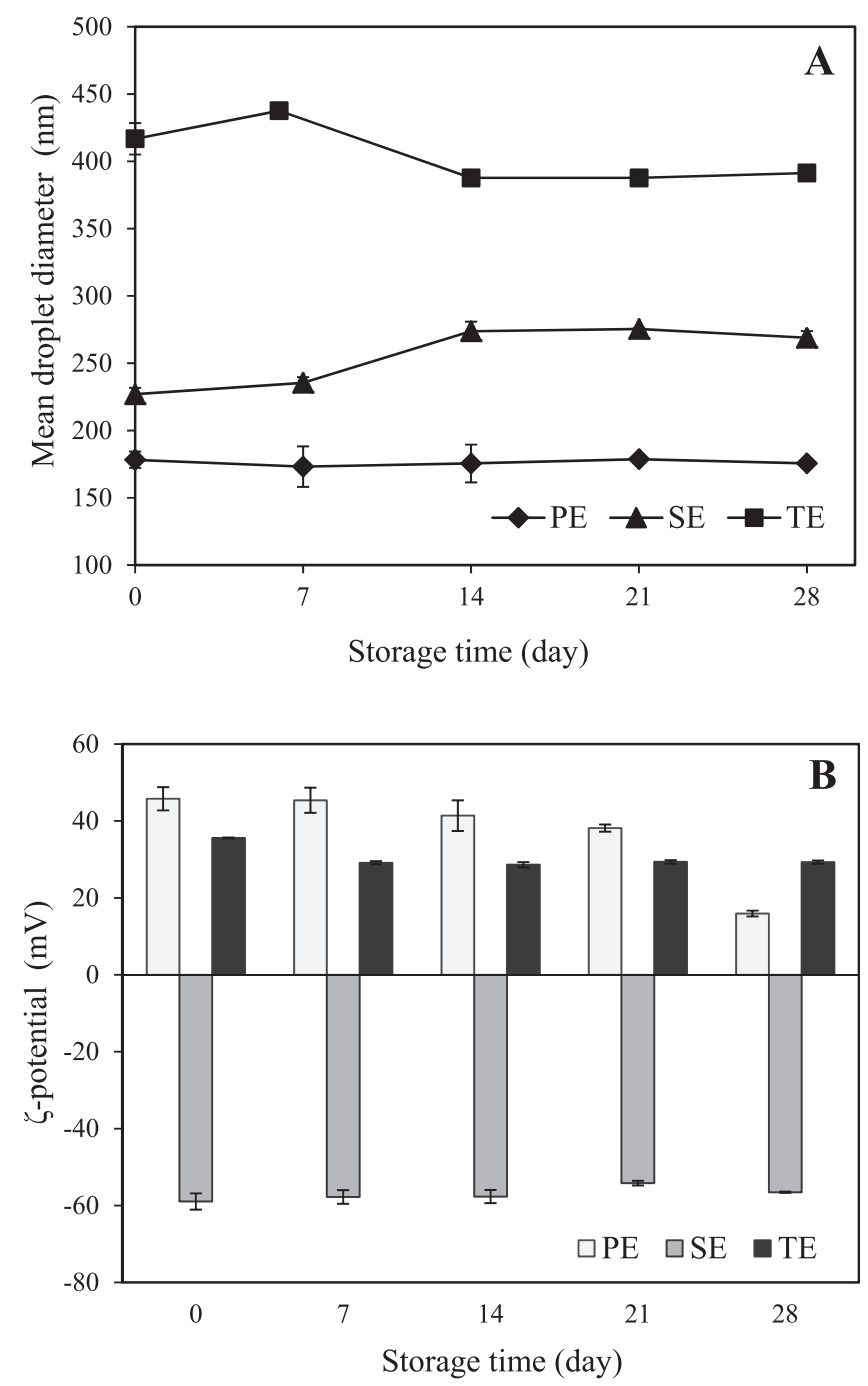

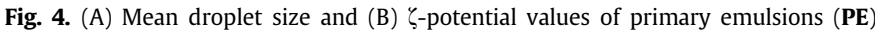
( $0.01 \%$ resveratrol, $5 \%$ corn oil and $1.90 \%$ lactoferrin), secondary emulsions (SE) $(0.002 \%$ resveratrol, $1 \%$ corn oil, $0.38 \%$ lactoferrin and $0.22 \%$ alginate) and tertiary emulsions (TE) $(0.0002 \%$ resveratrol, $0.090 \%$ corn oil, $0.030 \%$ lactoferrin, $0.020 \%$ alginate and $0.036 \% \varepsilon$-poly-L-lysine) during storage.
(Marudova, Lang, Brownsey, \& Ring, 2005). Despite these events, droplet sizes of tertiary emulsions did not show further changes during storage.

The $\zeta$-potential values of single-layer and multilayer emulsions are shown in Fig. 4B. Primary emulsions exhibited a remarkable decrease in the $\zeta$-potential from $45.8 \mathrm{mV}$ to $15.9 \mathrm{mV}$ after 4 weeks, which indicated changes in the net charge of the protein-coated droplets. The decrease in the positive interfacial charge of droplets might be related with the protein folding and unfolding located at the $\mathrm{o} / \mathrm{w}$ interface, probably originated by a disulfide shuffling or crosslinking mechanisms. Other factors might also have an effect on the interfacial properties of lactoferrin-coated droplets, such as the adsorption of positive mineral ions, interactions with oxygen or metals, or even the production of free fatty acids coming from the lipids breakdown of the disperse phase. These results are in concordance with those previously reported for lactoferrin stabilized emulsions, where a decreased in the positive $\zeta$-potential was observed after 14 days of storage (Mao et al., 2013). In another study, citral emulsions stabilized with milk proteins presented changes in the $\zeta$-potential after four weeks (Xiang, Liu, Fan, \& Gao, 2015).

On the contrary, secondary emulsions did not show variations in the $\zeta$-potential after four weeks. Results suggest that the presence of an additional interfacial alginate layer could increase the emulsion stability, probably by avoiding interactions between lactoferrin molecules and other reactive species or decreasing redox reactions within the protein located at the $\mathrm{o} / \mathrm{w}$ interface. The $\zeta$-potential of tertiary emulsions also remained stable during storage time, with only a slight decrease from $35.6 \pm 0.15 \mathrm{mV}$ to $29.2 \pm 0.42 \mathrm{mV}$ after 7 days. From the second to the fourth storage week, the $\zeta$-potential of tertiary emulsions did not present significant differences.

\subsection{Microstructure}

The microstructure of single-layer and multilayer emulsions was observed by TEM (Fig. 5). The morphology of lactoferrin-coated oil droplets in primary emulsions showed a well-defined spherical shape surrounded by a discrete interface corresponding to lactoferrin layer (Fig. 5A). The droplet sizes observed by TEM are in concordance with those obtained by dynamic light scattering. The lactoferrin/alginate-coated droplets in secondary emulsions were also spherical with a light inner region and a slightly dark outer region conforming the shell, which is presumably the two-layer coating (Fig. 5B). In the third case, the oil droplets coated by three layers (lactoferrin, alginate and $\varepsilon$-poly-L-lysine) were characterized by a light core and a visible intense black coating that corresponded to the multilayer coating (Fig. 5C). These results confirmed that emulsions showed different microstructures depending on the layer composition on droplets.

\subsection{Changes in the antioxidant activity during storage}

The DPPH radical scavenging activity of primary, secondary and tertiary emulsions containing resveratrol was studied during four weeks (Fig. 6). Also, the antioxidant activity of resveratrol-enriched corn oil was assessed. A significant decrease in the antioxidant activity of resveratrol-loaded oil was observed from $67.8 \%$ (day 0 ) to $53.0 \%$ after four weeks. This was attributed to the chemical instability of resveratrol under environmental conditions. Numerous studies have shown the high susceptibility of resveratrol to degradation by light, pH and temperature (Leiro et al., 2004; Zupančič et al., 2015). It has been described that resveratrol molecules can change rapidly from trans- to cis-isomers under UV light exposure, therefore reducing its biological activity (e.g. antioxidant activity). 
A

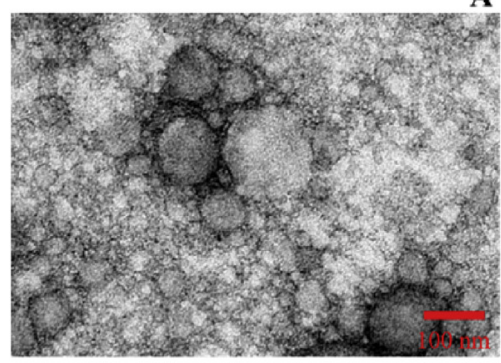

B

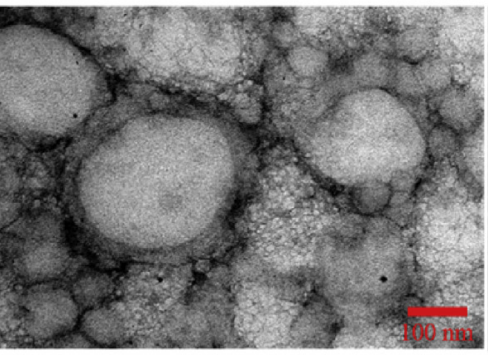

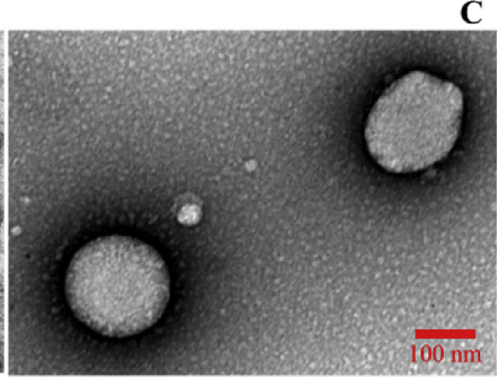

Fig. 5. Images obtained by Transmission Electron Microscopy of (A) primary emulsions, (B) secondary emulsions, and (C) tertiary emulsions. The magnification was $10.000 x$.

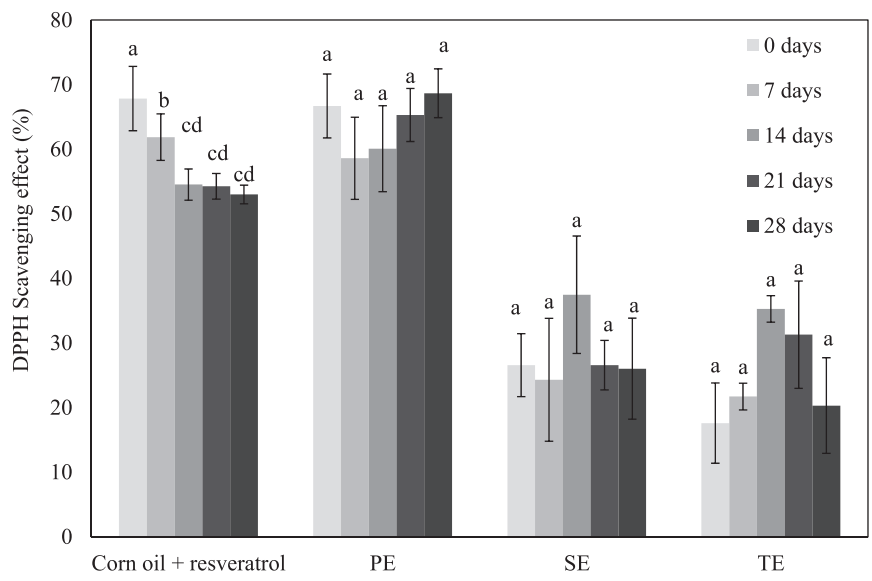

Fig. 6. Images obtained by Transmission Electron Microscopy of (A) primary emulsions, (B) secondary emulsions, and (C) tertiary emulsions. The magnification was $10.000 \mathrm{x}$.

On the other hand, no significant differences were observed in the antioxidant activity of primary emulsions stored during four weeks $(p<0.05)$. In general, the antioxidant activity of secondary and tertiary emulsions were lower than in primary emulsions. However, the initial resveratrol concentration was also lower in multilayer emulsions due to their dilution during preparation, which might partially explain the differences in the antioxidant activity of emulsions. Nevertheless, the antioxidant activity of multilayer emulsions did not present significant changes during storage. Previous studies have reported the interactions between milk proteins and resveratrol. Protein-polyphenol complexes may improve resveratrol functionality, for instance, by increasing the solubility and photo-stability (Liang, Tajmir-Riahi, \& Subirade, 2008). Hence the presence of lactoferrin at the o/w interface might have led to interactions with resveratrol dissolved in the disperse phase that could have helped retain resveratrol functionality during storage.

Interestingly, the DPPH radical scavenging activity of tertiary and secondary emulsions was very similar, although the concentration of resveratrol in tertiary emulsions was 10 -fold lower than in secondary emulsions. Some biopolymers adsorbed at the o/w interface may also act as antioxidants, thus contributing to the overall radical scavenging activity of the emulsions. Previous studies have shown that polypeptides, such as $\varepsilon$-poly-L-lysine, may exhibit certain antioxidant activity (Pan \& Nitin, 2015; Tikekar, Hernandez, Land, \& Nitin, 2013).

\section{Conclusions}

Multilayer emulsions containing resveratrol were obtained by the electrostatic deposition of lactoferrin, alginate and $\varepsilon$-poly-Llysine. The biopolymer concentration has a marked effect on the formation of multilayer emulsions. For instance, a very low concentration of either alginate or $\varepsilon$-poly-L-lysine resulted in extensive flocculation, which was attributed to the bridging flocculation and charge neutralization. At the highest $\varepsilon$-poly-L-lysine concentration, tertiary emulsions were also unstable, probably due to a depletion flocculation effect. On the other hand, the droplet size of singlelayer and multilayer emulsions did not present significant differences during storage. However, there was a decrease in the magnitude of the positive $\zeta$-potential in primary emulsions, which was not observed in multilayer emulsions during storage. The antioxidant activity of all emulsions containing resveratrol remained stable during storage, but decreased in resveratrolenriched oil. This study provides important information concerning the formation and stability of multilayer emulsions containing resveratrol, which might be useful for the design of delivery systems of active ingredients with food interest.

\section{Acknowledgments}

This research was supported by the Ministerio de Ciencia e Innovación (Spain) throughout the projects AGL2009-11475 and ALG2012-35635, and by the Portuguese Foundation for Science and Technology (FCT) under the scope of the strategic funding of UID/ BIO/04469/2013 unit and COMPETE 2020 (POCI-01-0145-FEDER006684), Project RECI/BBB-EBI/0179/2012 (FCOMP-01-0124FEDER-027462) and FCT Strategic Project of UID/BIO/04469/2013 unit. The authors also thank the Project "BioInd - Biotechnology and Bioengineering for improved Industrial and Agro-Food processes, REF. NORTE-07-0124-FEDER-000028" Co-funded by the Programa Operacional Regional do Norte (ON.2 - O Novo Norte), QREN, FEDER. The author A. Acevedo-Fani thanks the University of Lleida for the pre-doctoral grant. The author H. D. Silva, (SFRH/BD/81288/ 2011 ) is the recipient of a fellowship from the Fundação para a Ciência e Tecnologia (FCT, Portugal). The authors would like to acknowledge to Rui Fernandes from IBMC, University of Porto, for assistance in taking the TEM microphotographs.

\section{References}

Amri, A., Chaumeil, J. C., Sfar, S., \& Charrueau, C. (2012). Administration of resveratrol: What formulation solutions to bioavailability limitations? Journal of Controlled Release: Official Journal of the Controlled Release Society, 158(2), 182-193. http://dx.doi.org/10.1016/j.jconrel.2011.09.083.

Benjamin, O., Silcock, P., Leus, M., \& Everett, D. W. (2012). Multilayer emulsions as delivery systems for controlled release of volatile compounds using $\mathrm{pH}$ and salt triggers. Food Hydrocolloids, 27(1), 109-118. http://dx.doi.org/10.1016/ j.foodhyd.2011.08.008.

Bokkhim, H., Bansal, N., GrØndahl, L., \& Bhandari, B. (2013). Physico-chemical properties of different forms of bovine lactoferrin. Food Chemistry, 141(3), 3007-3013. http://dx.doi.org/10.1016/j.foodchem.2013.05.139.

Bokkhim, H., Bansal, N., Grøndahl, L., \& Bhandari, B. (2016). Characterization of alginate-lactoferrin beads prepared by extrusion gelation method. Food 
Hydrocolloids, 53, 270-276. http://dx.doi.org/10.1016/j.foodhyd.2014.12.002.

Bortnowska, G. (2015). Multilayer oil-in-water Emulsions: Formation, characteristics and application as the carriers for lipophilic bioactive food components - a review. Polish Journal of Food and Nutrition Sciences, 65(3), 157-166. http:// dx.doi.org/10.2478/v10222-012-0094-0.

Bouyer, E., Mekhloufi, G., Rosilio, V., Grossiord, J.-L., \& Agnely, F. (2012). Proteins, polysaccharides, and their complexes used as stabilizers for emulsions: Alternatives to synthetic surfactants in the pharmaceutical field? International Journal of Pharmaceutics, 436(1-2), 359-378. http://dx.doi.org/10.1016/ j.ijpharm.2012.06.052.

Brown, V. A., Patel, K. R., Viskaduraki, M., Crowell, J. A., Perloff, M., Booth, T. D., ... Brenner, D. E. (2010). Repeat dose study of the cancer chemopreventive agent resveratrol in healthy volunteers: safety, pharmacokinetics, and effect on the insulin-like growth factor axis. Cancer Research, 70(22), 9003-9011. http://dx.doi.org/10.1158/0008-5472.CAN-10-2364.

Cerqueira, M. A., Pinheiro, A. C., Silva, H. D., Ramos, P. E., Azevedo, M. A., FloresLópez, M. L., et al. (2014). Design of bio-nanosystems for oral delivery of functional compounds. Food Engineering Reviews, 6(1-2), 1-19. http:// dx.doi.org/10.1007/s12393-013-9074-3.

Chang, Y., McLandsborough, L. A., \& McClements, D. J. (2014). Interaction of cationic antimicrobial ( $\varepsilon$-polylysine) with food-grade biopolymers: Dextran, chitosan, carrageenan, alginate, and pectin. Food Research International, 64, 396-401. http://dx.doi.org/10.1016/i.foodres.2014.07.002.

Choi, A.-J., Kim, C.-T. C.-J., Cho, Y.-J., Hwang, J.-K., \& Kim, C.-T. C.-J. (2011). Characterization of Capsaicin-Loaded Nanoemulsions Stabilized with Alginate and Chitosan by Self-assembly. Food and Bioprocess Technology, 4(6), 1119-1126. http://dx.doi.org/10.1007/s11947-011-0568-9.

Cho, Y.-H., \& McClements, D. J. (2009). Theoretical stability maps for guiding preparation of emulsions stabilized by Protein-Polysaccharide interfacial complexes. Langmuir, 25(12), 6649-6657. http://dx.doi.org/10.1021/la8006684.

Davidov-Pardo, G., Gumus, C. E., \& McClements, D. J. (2016). Lutein-enriched emulsion-based delivery systems: Influence of $\mathrm{pH}$ and temperature on physical and chemical stability. Food Chemistry, 196, 821-827. http://dx.doi.org/10.1016/ j.foodchem.2015.10.018.

Davidov-Pardo, G., \& McClements, D. J. (2014). Resveratrol encapsulation: Designing delivery systems to overcome solubility, stability and bioavailability issues. Trends in Food Science \& Technology, 38(2), 88-103. http://dx.doi.org/10.1016/ j.tifs.2014.05.003.

Dickinson, E. (2003). Hydrocolloids at interfaces and the influence on the properties of dispersed systems. Food Hydrocolloids, 17(1), 25-39. Retrieved from http:// www.sciencedirect.com/science/article/pii/S0268005X01001205.

Fioramonti, S. A., Arzeni, C., Pilosof, A. M. R., Rubiolo, A. C., \& Santiago, L. G. (2015). Influence of freezing temperature and maltodextrin concentration on stability of linseed oil-in-water multilayer emulsions. Journal of Food Engineering, 156, 31-38. http://dx.doi.org/10.1016/j.jfoodeng.2015.01.013.

Guzey, D., \& McClements, D. J. (2006). Formation, stability and properties of multilayer emulsions for application in the food industry. Advances in Colloid and Interface Science, 128-130, 227-248. http://dx.doi.org/10.1016/ j.cis.2006.11.021.

Heurtault, B. (2003). Physico-chemical stability of colloidal lipid particles. Biomaterials, 24(23), 4283-4300. http://dx.doi.org/10.1016/S0142-9612(03)003314.

Hosseini, S. M. H., Emam-Djomeh, Z., Sabatino, P., \& Van der Meeren, P. (2015). Nanocomplexes arising from protein-polysaccharide electrostatic interaction as a promising carrier for nutraceutical compounds. Food Hydrocolloids, 50, 16-26. http://dx.doi.org/10.1016/j.foodhyd.2015.04.006.

Kim, S., Jin, Y., Choi, Y., \& Park, T. (2011). Resveratrol exerts anti-obesity effects via mechanisms involving down-regulation of adipogenic and inflammatory processes in mice. Biochemical Pharmacology, 81(11), 1343-1351. http://dx.doi.org/ 10.1016/j.bcp.2011.03.012.

Leiro, J., Alvarez, E., Arranz, J. A., Laguna, R., Uriarte, E., \& Orallo, F. (2004). Effects of cis-resveratrol on inflammatory murine macrophages: Antioxidant activity and down-regulation of inflammatory genes. Journal of Leukocyte Biology, 75(6), 1156-1165. http://dx.doi.org/10.1189/jlb.1103561.

Lesmes, U., Sandra, S., Decker, E. A., \& McClements, D. J. (2010). Impact of surface deposition of lactoferrin on physical and chemical stability of omega-3 rich lipid droplets stabilised by caseinate. Food Chemistry, 123(1), 99-106. http:// dx.doi.org/10.1016/j.foodchem.2010.04.007.

Liang, L., Tajmir-Riahi, H. A., \& Subirade, M. (2008). Interaction of $\beta$-lactoglobulin with resveratrol and its biological implications. Biomacromolecules, 9(1), 50-56. http://dx.doi.org/10.1021/bm700728k.

Liu, F., Wang, D., Sun, C., McClements, D. J., \& Gao, Y. (2016). Utilization of interfacial engineering to improve physicochemical stability of $\beta$-carotene emulsions: Multilayer coatings formed using protein and protein-polyphenol conjugates. Food Chemistry, 205, 129-139. http://dx.doi.org/10.1016/ j.foodchem.2016.02.155.

Mao, Y., Dubot, M., Xiao, H., \& McClements, D. J. (2013). Interfacial engineering using mixed protein systems: Emulsion-based delivery systems for encapsulation and stabilization of $\beta$-carotene. Journal of Agricultural and Food Chemistry, 61(21), 5163-5169. http://dx.doi.org/10.1021/jf401350t.

Marudova, M., Lang, S., Brownsey, G. J., \& Ring, S. G. (2005). Pectin-chitosan multilayer formation. Carbohydrate Research, 340(13), 2144-2149. http:// dx.doi.org/10.1016/j.carres.2005.07.004.
McCarthy, N. A., Kelly, A. L., O'Mahony, J. A., \& Fenelon, M. A. (2014). Sensitivity of emulsions stabilised by bovine $\beta$-casein and lactoferrin to heat and $\mathrm{CaCl} 2$. Food Hydrocolloids, 35, 420-428. http://dx.doi.org/10.1016/j.foodhyd.2013.06.021.

McClements, D. J. (2000). Comments on viscosity enhancement and depletion flocculation by polysaccharides. Food Hydrocolloids, 14(2), 173-177. Retrieved from http://www.sciencedirect.com/science/article/pii/S0268005X9900065X.

McClements, D. J. (2005). In C. Press (Ed.), Food emulsions: Principles, practices, and techniques. Boca Raton, Fla: CRC Press. Retrieved from http://cataleg.udl.cat/ record $=$ b1331041 S11*cat.

McClements, D. J., Decker, E. A., Park, Y., \& Weiss, J. (2009). Structural design principles for delivery of bioactive components in nutraceuticals and functional foods. Critical Reviews in Food Science and Nutrition, 49(6), 577-606. http:// dx.doi.org/10.1080/10408390902841529.

McClements, D. J., \& Rao, J. (2011). Food-grade nanoemulsions: Formulation, fabrication, properties, performance, biological fate, and potential toxicity Critical Reviews in Food Science and Nutrition, 51(4), 285-330. http://dx.doi.org/ 10.1080/10408398.2011.559558.

Nielsen, N. S., Petersen, A., Meyer, A. S., Timm-Heinrich, M., Jacobsen, C. Nielsen, N. S., ... Jacobsen, C. (2004). Effects of lactoferrin, phytic acid, and EDTA on oxidation in two food emulsions enriched with long-chain polyunsaturated fatty acids. Journal of Agricultural and Food Chemistry, 52(25), 7690-7699. http://dx.doi.org/10.1021/jf0492316.

Noshad, M., Mohebbi, M., Koocheki, A., \& Shahidi, F. (2015). Influence of interfacial engineering on stability of emulsions stabilized with soy protein isolate. Journal of Dispersion Science and Technology, 37(1), 56-65. http://dx.doi.org/10.1080/ 01932691.2015.1027907.

O'Regan, J., Ennis, M. P., \& Mulvihill, D. M. (2009). Milk proteins. In G. Phillips, \& P. A. Williams (Eds.), Handbook of hydrocolloids (2nd ed., pp. 298-343). Boca ratón, FL: CRC Press and Woodhead Publishing.

Pan, Y., \& Nitin, N. (2015). Effect of layer-by-layer coatings and localization of antioxidant on oxidative stability of a model encapsulated bioactive compound in oil-in-water emulsions. Colloids and Surfaces. B, Biointerfaces, 135, 472-480. http://dx.doi.org/10.1016/j.colsurfb.2015.08.003.

Park, S.-J., Ahmad, F., Philp, A., Baar, K., Williams, T., Luo, H., ... Chung, J. H. (2012) Resveratrol ameliorates aging-related metabolic phenotypes by inhibiting cAMP phosphodiesterases. Cell, 148(3), 421-433. http://dx.doi.org/10.1016/ j.cell.2012.01.017.

Pinheiro, A. C., Coimbra, M. A., \& Vicente, A. A. (2016). In vitro behaviour of curcumin nanoemulsions stabilized by biopolymer emulsifiers - effect of interfacial composition. Food Hydrocolloids, 52, 460-467. http://dx.doi.org/10.1016/ j.foodhyd 2015.07.025.

Pinheiro, A. C., Bourbon, A. I., Cerqueira, M. A., Maricato, É., Nunes, C. Coimbra, M. A., \& Vicente, A. A. (2015). Chitosan/fucoidan multilayer nanocapsules as a vehicle for controlled release of bioactive compounds. Carbohydrate Polymers, 115, 1-9. http://dx.doi.org/10.1016/j.carbpol.2014.07.016.

Schmelz, T., Lesmes, U., Weiss, J., \& McClements, D. J. (2011). Modulation of physicochemical properties of lipid droplets using $\beta$-lactoglobulin and/or lactoferrin interfacial coatings. Food Hydrocolloids, 25(5), 1181-1189. http://dx.doi.org 10.1016/j.foodhyd.2010.11.005.

Sessa, M., Tsao, R., Liu, R., Ferrari, G., \& Donsì, F. (2011). Evaluation of the stability and antioxidant activity of nanoencapsulated resveratrol during in vitro digestion. Journal of Agricultural and Food Chemistry, 59(23), 12352-12360. http://dx.doi.org/10.1021/jf2031346.

Shchukina, E. M., \& Shchukin, D. G. (2012). Layer-by-layer coated emulsion microparticles as storage and delivery tool. Current Opinion in Colloid \& Interface Science, 17(5), 281-289. http://dx.doi.org/10.1016/j.cocis.2012.06.003.

Shimoni, G., Shani Levi, C., Levi Tal, S., \& Lesmes, U. (2013). Emulsions stabilization by lactoferrin nano-particles under in vitro digestion conditions. Food Hydrocolloids, 33(2), 264-272. http://dx.doi.org/10.1016/j.foodhyd.2013.03.017.

Tikekar, R. V., Hernandez, M., Land, D. P., \& Nitin, N. (2013). “Click chemistry” based conjugation of lipophilic curcumin to hydrophilic $\varepsilon$-polylysine for enhanced functionality. Food Research International, 54(1), 44-47. http://dx.doi.org/ 10.1016/j.foodres.2013.06.004.

Trela, B., \& Waterhouse, A. (1996). Resveratrol: Isomeric molar absorptivities and stability. Journal of Agricultural and Food Chemistry, 44(5), 1253-1257. http:// dx.doi.org/10.1021/jf9504576.

Witte, A. V., Kerti, L., Margulies, D. S., \& Flöel, A. (2014). Effects of resveratrol on memory performance, hippocampal functional connectivity, and glucose metabolism in healthy older adults. The Journal of Neuroscience: The Official Journal of the Society for Neuroscience, 34(23), 7862-7870. http://dx.doi.org/ 10.1523/JNEUROSCI.0385-14.2014.

Xiang, J., Liu, F., Fan, R., \& Gao, Y. (2015). Physicochemical stability of citral emulsions stabilized by milk proteins (lactoferrin, $\alpha$-lactalbumin, $\beta$-lactoglobulin) and beet pectin. Colloids and Surfaces a: Physicochemical and Engineering Aspects, 487, 104-112. http://dx.doi.org/10.1016/j.colsurfa.2015.09.033.

Xu, Q., \& Si, L.-Y. (2012). Resveratrol role in cardiovascular and metabolic health and potential mechanisms of action. Nutrition Research, 32(9), 648-658. http:// dx.doi.org/10.1016/j.nutres.2012.07.002.

Ye, A., \& Singh, H. (2007). Formation of multilayers at the interface of oil-in-water emulsion via interactions between lactoferrin and ??-lactoglobulin. Food Biophysics, 2(4), 125-132. http://dx.doi.org/10.1007/s11483-007-9029-4.

Yoshida, T., Hiraki, J., \& Nagasawa, T. (2005). ع-Poly-L -lysine. In A. Steinbüchel, \& S. K. Rhee (Eds.), Polysaccharides and polyamides in the food industry (pp. 
671-685). Weinheim: Wiley-VCH.

Zhao, J., Wei, T., Wei, Z., Yuan, F., \& Gao, Y. (2015). Influence of soybean soluble polysaccharides and beet pectin on the physicochemical properties of lactoferrin-coated orange oil emulsion. Food Hydrocolloids, 44, 443-452. http:// dx.doi.org/10.1016/j.foodhyd.2014.10.025.
Zupančič, Š., Lavrič, Z., \& Kristl, J. (2015). Stability and solubility of trans-resveratrol are strongly influenced by $\mathrm{pH}$ and temperature. European Journal of Pharmaceutics and Biopharmaceutics: Official Journal of Arbeitsgemeinschaft Für Pharmazeutische Verfahrenstechnik e.V, 93, 196-204. http://dx.doi.org/10.1016/ j.ejpb.2015.04.002. 